\title{
3. Innovation policy prior to 2020
}

\subsection{INTRODUCTION}

Innovation is credited with many things, including the creation of jobs and economic growth. Governments promote innovation in order to benefit from these outcomes and for decades, the emphasis has been on innovation in the business sector. That continues, but there is also interest in innovation in the public sector, and in types of innovation that can occur in any economic sector, such as innovation in the informal economy (Kraemer-Mbula and Wunsch-Vincent 2016) and social innovation (Moulaert et al. 2013; Moulaert and MacCallum 2019).

\subsubsection{Some History}

The study of innovation, and related policy, goes back to the 1930s (Schumpeter 1934), but it was not until 1992 that guidelines for the statistical measurement of innovation were formalised (OECD 1992). The European Union Community Innovation Survey (CIS) began, for reference year 1992, and provided the data to populate statistics used to produce indicators that could support the development of innovation policy. It is this connection between innovation policy and measurement that is the subject of this book.

Another high-level intervention in the development of innovation research, over the last 15 years, was a proposal by John Marburger, then the Director of the Office of Science and Technology Policy in the Executive Office of the President of the United States, to promote the 'Science of Science Policy'(Marburger 2005). Later in 2006, at the OECD Blue Sky Forum II (Marburger 2007), the proposal was extended to include innovation.

The National Science Foundation (NSF) responded by creating a programme for the 'Science of Science and Innovation Policy (SciSIP). The NSF announced several SciSIP solicitations with a view to developing a community of practice, working on a better understanding of science 
and innovation policy and measurement, and a peer group of policy developers, managers and users.

The EU, the OECD and countries, including the US, were studying the need for science and innovation policy which, in turn, required statistical measurement and indicators. These issues are discussed further in Chapter 10, including the role of institutions doing research on science and innovation policy.

'Innovation', in the context of the SciSIP project, was that of the third edition of the Oslo Manual (OECD/Eurostat 2005). Products were new or improved and introduced on the market and processes were also new or improved and brought into use by the firm. If there was an implemented policy, its objective was to promote the activity of innovation in the business sector. The SciSIP project was to understand how innovation happened and how innovation policy could be improved. It was not there to propose policy but to examine which implemented innovation policies worked better than others.

A key point made by Marburger at the OECD Blue Sky Forum II (OECD 2007) was that 'in the face of a rapid global change, old correlations do not have predictive value' (Marburger 2007: 32). It was supported by Chris Freeman and Luc Soete, at the same forum (Freeman and Soete 2007: 272), who observed that 'the link between the measurement of national STI activities and their national economic impact, while always subject to debate, particularly within the context of small countries, has now become so loose that national STI indicators are in danger of no longer providing relevant economic policy insights'. The purpose of the OECD Blue Sky Forums was to examine the use of current indicators of science, technology and innovation (STI) and the need for better indicators and new indicators. Both Marburger (2007) and Freeman and Soete (2007) provided serious challenges to make STI indicators more relevant and SciSIP was one approach to a solution for such problems (Gault 2011).

The SciSIP work has gone on, supported by NSF, and Al Teich (2018) has provided a comprehensive review of the SciSIP process and its achievements in more than a decade of research. Creating a new specialty in the social science community takes time, and that goal is yet to be realised. 
Meanwhile, in September 2019, a 'Dear Colleague Letter' was issued by NSF (2019) which made the following statement about SciSIP:

Science of Science: Discovery, Communication, and Impact

https://www.nsf.gov/funding/pgm_summ.jsp?pims_id=505730: This evolution of the former Science and Innovation Policy Program focuses on basic research that can increase the productivity of scientific workflows, our nation's capacity to communicate it accurately and effectively, and the value of that work to society.

The Science of Science: Discovery, Communication, Impact (SoS: DCI) Program removes 'innovation' and 'policy' to focus on the science of science. Fortunately, there are many research groups studying innovation policy. Another Marburger (2007) proposal is discussed in Chapter 10 and his work is reviewed in Marburger and Crease (2015).

\subsubsection{International and Supranational Organisations}

Because of the importance of innovation, international and supranational organisations publish information on innovation policy (OECD 2011, 2014;月 EU 2013; GTIPA 2019) and delegations discuss policy issues in their committees. The EU provides fact sheets to guide researchers, one of which is The Innovation Policy Fact Sheet. No one expects there to be a single solution to implementing effective innovation policies, but the objective is to see what works and what does not in other countries. This has given rise to an extensive literature on the theory and practice of innovation policy (Smits et al. 2010; Edler et al. 2016) and research institutes that focus on the subject (the Science Policy Research Unit at the University of Sussex and the Manchester Institute of Innovation Research and its predecessors at the University of Manchester are examples in the UK. Internationally, there is the European Forum for the Studies of Policies of Research and Innovation (EUSPRI)).

\subsubsection{OECD and Innovation Strategy}

The OECD published an innovation strategy in 2015 (OECD 2015a), an update of the 2010 strategy (OECD 2010a) which had a separate report on measurement (OECD 2010b). The 2015 strategy provides advice, 
rather than specific policies for countries. It proposes five characteristics of a positive environment for innovation (OECD 2015a: 12):

- a skilled workforce

- a sound business environment

- a strong and efficient system for knowledge creation and diffusion

- policies that encourage innovation and entrepreneurial activity

- a strong focus on governance and implementation.

These characteristics are supported by five priorities (OECD 2015a: 12). They are to:

- strengthen investment in innovation and foster business dynamism

- invest in, and shape, an efficient system of knowledge creation and diffusion

- seize the benefits of the digital economy

- foster talent and skills and optimise their use

- improve the governance and implementation of policies for innovation.

The positive environment and the priorities demonstrate that countries have, to some extent, moved on from treating R\&D policy as innovation policy, although countries with a small business sector may still focus on $\mathrm{R} \& \mathrm{D}$ rather than innovation.

The concept of a system was discussed in Chapter 2. The importance of the digital economy is a priority for the OECD innovation strategy, and this in 2015 when the digital economy was just beginning to have an impact. Finally, governance and implementation of polices are priorities. Both are discussed in Chapter 5.

The OECD innovation strategy (OECD 2015a) does not deal with sectors other than the business sector. Innovation in the public sector is considered in a separate publication (OECD 2015b). In the 2010 version of the OECD innovation strategy, the statistical measurement of innovation was treated separately (OECD 2010b). This is discussed in Part III.

\subsubsection{European Union and Innovation Policy}

The Innovation Policy Fact Sheet describes activities related to policy and provides links to innovation projects.

The EU innovation policy is not isolated. It is linked to policies on employment, competitiveness, environment, industry and energy and 
the role of innovation is explicit 'to turn research results into new and better services and products in order to remain competitive in the global marketplace and improve the quality of life of Europe's citizens'. The linking of policy objectives is consistent with a systems approach to innovation policy.

In 2010, the EU introduced the Innovation Union and it has produced the Innovation Union Scoreboard (discussed in Chapter 4), the Regional Innovation Scoreboard and the Innobarometer. The Innobarometer conducts an annual opinion poll asking businesses, and the public about innovation policy. The statement that 'innovation is made possible by research and education' makes clear the role of formal knowledge generation and of institutions of education.

A key point is that Horizon 2020, the EU's 8th Framework Programme (2014-20), is the first framework programme to integrate research and innovation. It also supports work on public sector and social innovation.

In 2015, the Commissioner responsible for research, science and innovation announced the European Innovation Council, which is under consideration for the successor to Horizon 2020. It is managed by members of the business community and it provides advice and support to businesses.

While the promotion of innovation through innovation policies is an active and current topic, there is also interest in how knowledge moves from one unit to another and how to support the transfer of knowledge from research institutions to firms that could then use it to support innovation (EU 2014).

In summary, there is significant interest in the EU and support for innovation in the business and the public sectors and for social innovation. The knowledge gained from this involvement could contribute to manuals, like the Oslo Manual, on the measurement of innovation in sectors other than the business sector and for innovation, in this case social innovation, that occurs in any economic sector. There is also interest in open innovation and the flow of knowledge between institutional units.

\subsection{INNOVATION IN STATISTICAL SURVEYS}

After years of R\&D policy dominating innovation policy, there is ample empirical evidence to show that, in the business sector, more firms innovate than do R\&D. Table 3.1 provides information from the NSF 2014 


\section{Table $3.1 \quad$ More firms innovate than do $R \& D$}

\begin{tabular}{llll}
\hline Firm characteristics & All firms & $\begin{array}{l}\text { Product or process } \\
\text { innovations }\end{array}$ & $\begin{array}{l}\text { No. of innovative } \\
\text { firms }\end{array}$ \\
\cline { 2 - 4 } & Number $(000)$ & Per cent & Number (000) \\
\hline All & 1273.3 & 15.4 & 196.1 \\
With R\&D & 53.5 & 69.5 & 37.4 \\
No R\&D & 1219.9 & 13.1 & 159.8 \\
\hline
\end{tabular}

Note: $\quad$ That more firms innovate than do R\&D is not peculiar to the US. Any country that runs an innovation survey and asks questions about $R \& D$ should be able to come to the same conclusion.

Source: Kindlon and Jankowski (2017: Table 3) and author calculation.

Business R\&D and Innovation Survey (BRDIS) (Kindlon and Jankowski 2017).

Two points in Table 3.1 are important for innovation policy. The first is that the propensity to innovate is higher for firms that do R\&D $(69.5$ per cent) than those that do not (13.1 per cent). The second is that 159,800 firms innovate but do no R\&D compared with the 37,400 firms that innovate and do R\&D.

There are two other empirical observations that should influence policy development. They are the correlation between the propensity to innovate and the size of firms, measured by employment (Kindlon and Jankowski 2017: Table 2), and the correlation between the propensity to innovate and the expenditure on R\&D by the firm (Kindlon and Jankowski 2017: Table 3). A summary of these observations is that large firms are likely to perform R\&D and to innovate, but there are many more small firms than there are large firms. What are the policies for them, and do they take account of firm size?

The innovation policy question is illustrated in Table 3.2 which can be populated with data from any country that runs an innovation survey. From Table 3.1, the number of firms in $\mathrm{C}$ is larger than in $\mathrm{E}$ and the policy question is whether, or not, to promote the performance of $R \& D$ by firms in C. Before doing that, the size effect should be examined, producing Table 3.2 for a series of firm sizes. There are firms that engage in innovation activities, but do not innovate, and some will do R\&D (D) and some not (B). The policy question is whether to provide an incentive to firms in $\mathrm{B}$ to move to $\mathrm{C}$ and firms in $\mathrm{D}$ to move to $\mathrm{E}$. Firms could also be encouraged to move from $\mathrm{B}$ to $\mathrm{D}$ and then to $\mathrm{E}$. What remains is how to deal with firms in A. 
Table 3.2 Reporting innovation in the business sector

\begin{tabular}{|c|c|c|c|c|}
\hline & \multirow[t]{2}{*}{ Innovative Firms } & \multicolumn{2}{|c|}{ Non-Innovative Firms } & \multirow[t]{2}{*}{ Total Firms } \\
\hline & & $\begin{array}{c}\text { Ongoing and/ } \\
\text { or abandoned } \\
\text { innovation activities } \\
\text { ONLY }\end{array}$ & $\begin{array}{c}\text { No innovation } \\
\text { activities }\end{array}$ & \\
\hline$R \& D$ performed & $\mathrm{E}$ & $\mathrm{D}$ & $\mathrm{n} / \mathrm{a}$ & \\
\hline $\begin{array}{l}\text { R\&D not } \\
\text { performed }\end{array}$ & $\mathrm{C}$ & B & A & \\
\hline Total Firms & & & & \\
\hline
\end{tabular}

Note: This table was first presented at a workshop of the African Science,

Technology and Innovation Indicator (ASTII) initiative in Windhoek, Namibia on 25 May 2017.

Source: The author.

A policy consideration is whether to promote the growth of firms, assuming that as the firm grows in size, the firm strategy will recognise the need for the performance of R\&D if it is going to be able to bring product innovations to the market. Promoting growth is also an issue in countries that provide R\&D incentives to small firms, with no incentive or a less attractive incentive to larger firms. Such a policy may promote $\mathrm{R} \& \mathrm{D}$, but not growth.

\subsection{SOME INNOVATION POLICIES}

Innovation policies over the last five years have had many objectives. Some are reviewed here.

\subsubsection{Innovation Related to People}

Innovation requires knowledgeable people, and this leads to support for institutions of higher education to produce more graduates in the science, technology, engineering and mathematics (STEM) fields. This objective also has implications for primary and secondary school education and the need to prepare students for the courses they will enter in post-secondary institutions. It also raises a question of content.

With the use of artificial intelligence (AI) as part of innovation, there is a need to have people involved in innovation activities with a good knowledge of sociology and psychology as the new or improved products being offered, as product innovation, are designed to change the behav- 
iour of groups, and of individuals. This does not preclude the need for people with technical skills.

In addition to education, the health of people matters, if they are to be productive, and health is linked to human behaviour. After years of consuming food containing animal fat, salt and sugar, there is a population of obese people more likely to have type 2 diabetes, cardiovascular illness and the need to have hip and knee joints replaced. This is an example of a systems problem where the policy has to address the cause of the problem while also supporting medical research to deal with the immediate need to care for people with medical problems. Time is an important variable in the development of innovation policy and the analysis of the implemented policy.

Demographic distributions can influence innovation policy. In the developed world, there is an ageing population and people need new ways to support them in their old age. While this is a humanitarian undertaking, learning how to make the lives of the elderly better can lead to marketable products (Gault 2010: 106; Aho et al. 2013). In many developing countries, especially in Africa, the median age is quite low (in Rwanda it is 19) and the challenge is to engage a young population in productive activities.

\subsubsection{Knowledge Generation and Transfer}

\section{Knowledge generation}

The formal generation of knowledge, $\mathrm{R} \& \mathrm{D}$, is an innovation activity (OECD/Eurostat 2018: 85) and, as with all other innovation activities, it does not necessarily result in innovation. R\&D can happen in all sectors of the economy and there are innovation policies directed at promoting $\mathrm{R} \& \mathrm{D}$ in the business sector and in the public sector. There is also policy in support of transferring the knowledge from research institutions and institutions of higher education to firms in the business sector, either directly or through intermediaries.

The OECD has reviewed R\&D tax support and introduced a new OECD R\&D Tax Incentives Database (Appelt et al. 2019). One of the OECD countries that does not have R\&D tax incentives is Germany, but one is under review following the tabling by the government of a bill in May 2019. The bill, if it becomes law, will permit 25 per cent of eligible expenses on $R \& D$ (calculated on the basis of the cost of R\&D personnel), up to $€ 2,000,000$ per year, to be claimed as tax credit (the credit has a limit of $€ 15,000,000$ per $R \& D$ project). This also applies to $R \& D$ 
that has been contracted out. In this case the rate (of eligible expenses) remains at 25 per cent, but it applies only to 60 per cent of the personnel costs.

The EFI 2019 report (EFI-Commission of Experts for Research and Innovation 2019) supports an R\&D tax credit and refers to the 2017 EFI report (EFI-Commission of Experts for Research and Innovation (2017: 9) for potential courses of action. There are two: a tax credit on income tax proportional to a company's internal R\&D expenditures, or a tax credit on wage tax calculated on the basis of the $R \& D$ personnel costs incurred. The second was recommended. In both cases, the tax incentive is aimed at small and medium-sized enterprises (SMEs). However, the draft bill does not limit the potential tax credit to SMEs. Any firm may apply.

Focusing on SMEs, depending upon the type of R\&D tax credit, can create a barrier beyond which a SME may not wish to grow if it loses the tax incentive or the tax incentive changes. This issue is discussed by Drummond and Bentley (2010) in relation to the Scientific Research and Experimental Development (SR\&ED) tax benefit programme of Canada.

Another observation about $R \& D$ is that the population of $R \& D$ performers in the business sector is dominated by R\&D performing firms that do little R\&D and are sporadic in their performance. This has been demonstrated by Molotja et al. (2019) for South Africa and it confirms work done in Canada (Schellings and Gault 2002). See also Rammer and Schubert (2016).

\section{Knowledge transfer}

There are a number of policies promoting the transfer of knowledge in support of innovation. Firms can acquire R\&D results from outside of the firm if they have the capacity to absorb the knowledge. Policies dealing with education and training, which may be government policies or firm strategy, or both, can support this transfer of formal knowledge and its application.

The application of firms for vouchers which, if granted, allow the firm to pay institutions of higher education, or research institutes, for help in solving problems is becoming more common (OECD 2014: 160). It is also a way for firms that do no R\&D to gain knowledge needed for innovation.

Knowledge transfer is not limited to technical knowledge. Innovation policy can include the financial support for start-ups and the provision of 
knowledge needed to manage the funding. In August 2019, the German Federal Ministry of Economic Affairs and Energy released a list of funding programmes (BMWi 2019). The programmes are designed to support different financial needs at different stages of development of the client firms. One, the High-Tech Start-up Fund (HTGF), provides early-phase funding but also 'ensures that the management of young start-ups receives the necessary help and support'. This goes beyond financial support and supports a wider range of knowledge to be transferred.

While financing of innovation activities in firms is important, so also is proximity. Uyarra and Ramlogan (2016) have examined the effect of cluster policy on innovation. Their paper is part of the Compendium of Evidence on the Effectiveness of Innovation Policy Intervention Project undertaken by the Manchester Institute of Innovation Research (MIoIR), funded by the National Endowment for Science, Technology and the Arts (Nesta). At the OECD, there is earlier work on clusters (OECD 2009) where case studies are presented in seven countries and policy issues are reviewed. Since 2012, the Cluster Observatory, run privately by CSC in Stockholm, has supported researchers, policy makers and cluster organisations.

\section{Dealing with the future}

Country innovation policies address improvements for dealing with agriculture and food processing, renewable energy production and use, and transportation efficiency. The focus is more on what will happen than what is happening as a result of innovation in these areas.

Globally, there are the 17 UN Sustainable Development Goals (SDGs) and the objective of meeting the SDG targets by 2030. Eco-innovation is part of an international discourse and there is a plan to produce a manual on the subject (Kemp et al. 2019) to guide statistical measurement, analysis and policy learning. These are addressed in Chapter 9.

\subsection{INNOVATION POLICY IN COUNTRIES}

The OECD provided country profiles, including innovation policies, up to the 2014 Outlook (OECD 2014). The OECD-World Bank Innovation Policy Platform (IPP) has also been used as a valuable tool for understanding innovation policy, but it was archived on 1 July 2019. A source of country information is the European Commission/OECD International Survey on Science, Technology and Innovation Policy (STIP). The 
current version is the 2017 survey. The electronic platform is 'Research and Innovation' from the Research and Innovation Observatory Horizon 2020 Policy Support Facility (RIO - H2020 PSF). 19

While the emphasis in the RIO material is on R\&D, the search facility provides access to 'vouchers' and to those countries using a voucher policy for innovation. The digital economy is present, but it draws on the IPP which is no longer supported and does not include the most recent OECD Digital Economy Outlook (OECD 2017e). However, the RIO $\mathrm{H} 2020 \mathrm{PSF}$ is a potentially valuable tool that will grow in usefulness as it identifies and includes additional policy relevant topics.

The STIP Compass International Database on STI policies! provides access to the policies of participating countries. For example, a query on 'vouchers' generates 132 responses, 258 for the digital economy, 155 for social innovation. These are topics discussed later. The database also shows how many STI policy activities are engaged in by each country. This informs discussions, or recommendations, about 'whole of government', 'holistic' or 'fragmented' innovation policy.

In summary, these two databases provide relevant information on the innovation policies of countries and can be used by the reader to pursue issues raised later in this book. While there are many references to public sector innovation, the work cited was before the provision of a general definition of innovation in all economic sectors. The general definition is introduced in Chapter 6.

\subsection{NATIONAL INNOVATION SYSTEMS AND POLICY}

So far, the discussion has been on innovation policy with reference to innovation systems (Chapter 2) and statistical measurement of innovation. The extensive literature on National Innovation Systems (Freeman 1987; Lundvall 1992; Nelson 1993) has not been considered. Part of the reason is that this book is focused on a definition of innovation for use in all economic sectors (Chapter 6), supporting statistical measurement of innovation and innovation activities (Chapters 7 and 8) which lead to the production of innovation indicators that can be used to develop innovation policy and then to monitor and evaluate innovation policy, once it is implemented, leading to policy learning. The National Innovation System (NIS) goes beyond this basic approach. 
The definition of a NIS used by Lundvall et al. (2009) and also by Chaminade et al. (2018) is the following:

... an open, evolving and complex system that encompasses relationships within and between organisations, institutions and socio-economic structures which determine the rate and direction of innovation and competence-building from processes of science-based and experience-based learning.

This is a definition of a system, specifically a NIS, and it is not to be confused with a definition of innovation for the purpose of statistical measurement. It is elaborated upon in Chaminade et al. (2018: 70-3) and it is considered here because of its importance for innovation policy.

The emphasis is on learning and the diversity of learning suggesting that related policy deals with how learning is supported, whether it is experience-based or science-based. The different needs, and policies, in developing countries are noted. In Chapter 2 of this book, the system consisted of institutional units, engaged in activities, having linkages with other institutional units, resulting in outcomes and longer term impacts. Considering the NIS, learning could take place in the institutional unit as an innovation activity, or through a linkage which could be formal or informal with another institutional unit (a firm or a research institution, for example). All of these possibilities suggest different policy interventions.

The NIS definition stresses linkages not just with other institutional units but within the institutional unit. The linkages could include global value chains which may require a change in the organisation of the production of the institutional unit connected to the value chain.

Chaminade et al. (2018) raise the importance of the informal economy, especially in developing countries (Kraemer-Mbula and Wamae 2010; Kraemer-Mbula and Wunsch-Vincent 2016) and note the importance of understanding innovation, learning and competence building within the NIS. This topic is discussed further in Chapter 8, along with the implications for policy.

Structural issues in the NIS are raised, both economic and social, which could be regarded from a systems perspective as framework conditions as discussed in Chapter 2. These framework conditions may influence government policy, business strategy and behaviour of individuals and households. 


\subsection{CONCLUSION}

This chapter has looked at innovation policies now and how they are approached by the EU and the OECD, as well as by selected countries. Innovation has been confined to the business sector which is seen as a source of jobs and economic growth. While there is some reference to the public sector, and to social innovation, there is no single agreed definition of innovation outside of the business sector. The definition is an issue for Chapter 6 and then the application of the definition takes place in Chapter 10.

Presented in this chapter are the different approaches to innovation policy and what drives it. The question remains as to what extent R\&D, or knowledge gained from experience, dominate innovation and innovation policy.

\section{NOTES}

1. This programme is reviewed in Teich (2018) and is further discussed in Chapter 10.

2 OECD (2014) is cited, rather than more recent Outlooks, because it provides, in Chapter 9, STI country profiles which are still worth reading. Country profiles do not appear in the next two Outlooks, OECD (2016) and OECD (2018b), but note the change of the name of the publication with 'Innovation' replacing 'Industry'. In the Foreword to OECD (2016) reference is made to the European Commission/OECD International Survey on Science, Technology and Innovation Policy (STIP) as a source of indicators to monitor innovation policy. The OECD-World Bank Innovation Policy Platform (IPP) is also referenced. It was a valuable tool for understanding innovation policy, but it was archived on 1 July 2019. In the 2018 Outlook, use of the 2017 STIP (https://stip/oecd.org, accessed 17 March 2020) is acknowledged and it is a useful source of information on innovation policy.

3. See http://www.europarl.europa.eu/factsheets/en/sheet/67/innovation -policy (accessed 17 March 2020).

4 See https://ec.europa.eu/research/eic/index.cfm (accessed 17 March 2020).

5. This is the situation at the time of writing. Bills can be amended or withdrawn. If the tax credit is of interest, the reader is recommended to follow the progress of the bill. A source in English is Leyton.com.

6. See https://www.canada.ca/en/revenue-agency/services/scientific-research -experimental-development-tax-incentive-program.html (accessed 17 March 2020).

7. See https://www.bmwi.de/Redaktion/EN/Dossier/financing-for-start-ups -company-growth-and-innovations.html (accessed 17 March 2020).

8. The 20 reports are found at http://www.innovation-policy.org.uk/ compendium/ (accessed 17 March 2020). 
9. See http://www.clusterobservatory.eu/ (accessed 17 March 2020).

10. See also Edler et al. (2016).

11. https://stip.oecd.org (accessed 17 March 2020).

12. See Borrás and Edquist (2019) for a view on 'holistic' innovation policy. 